\title{
Chiral Ethylenebis(4,5,6,7-tetrahydro-1-indenyl)zirconium 2,2'-Biphenolate. Separation and Application to Asymmetric Polymerization
}

\author{
Shigeki Habaue, Hiroshi SaKamoto, and Yoshio Окамото ${ }^{\dagger}$ \\ Department of Applied Chemistry, School of Engineering, Nagoya University, \\ Chikusaku, Nagoya 464-01, Japan
}

(Received August 26, 1996)

\begin{abstract}
KEY WORDS Zirconocene / Enantiomer / Resolution / High-Performance Liquid Chromatography / Asymmetric Cyclopolymerization / 1,5-Hexadiene /
\end{abstract}

Enantiomerically pure ethylenebis(4,5,6,7-tetrahydro1-indenyl)zirconium dichloride (1) has become increasingly important as a precatalyst for catalytic asymmetric reactions in synthetic organic chemistry and polymer chemistry. ${ }^{1}$ However, the only method of preparation is kinetic resolution of $( \pm)-1$ with optically active lithium (1,1'-binaphthyl)-2,2'-diolate followed by removal of unreacted 1 with alumina. ${ }^{2-4}$ The binaphtholate adduct 2 can be converted to the optically pure 1 again. ${ }^{5}$ We recently reported the first successful resolution of racemic ethylenebis(4,5,6,7-tetrahydro-1-indenyl)zirconium derivatives by high-performance liquid chromatography (HPLC) on cellulose tris(3,5-dimethylphenylcarbamate) coated on silica-gel (Chiralcel OD). ${ }^{6,7}$ This paper reports a preparative separation of the optically pure ethylenebis $(4,5,6,7$-tetrahydro-1-indenyl)zirconium 2,2'-biphenolate (3) by HPLC and its application as a catalyst to the asymmetric cyclopolymerization of 1,5-hexadiene.

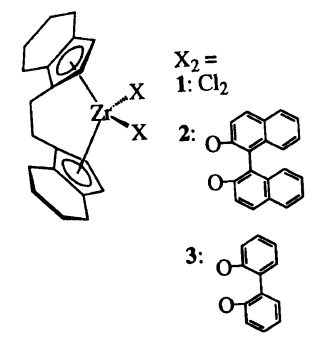

\section{EXPERIMENTAL}

\section{General}

${ }^{1} \mathrm{H}$ NMR spectra were measured on a Varian Gemini$2000(400 \mathrm{MHz})$ or UNITY-INOVA $(500 \mathrm{MHz})$ spectrometer in $\mathrm{CDCl}_{3}$ with tetramethylsilane as the internal standard. CD spectra were taken on a JASCO J-720L apparatus with a $0.1-\mathrm{mm}$ cell in $\mathrm{CHCl}_{3}$ solution. Optical rotation was measured with a JASCO DIP-181 polarimeter.

Toluene was distilled from $\mathrm{Na}$ wire, and then distilled again from $n$-BuLi under high vacuum just before use. The zirconocene complex $( \pm)-1$ was generously supplied by Tosoh Co. A co-catalyst methylaluminoxane (MAO) in toluene was kindly provided by Tosoh Akzo Co. 1,5Hexadiene (TCI) was distilled under high vacuum from calcium hydride just before polymerization.

$\dagger$ To whom all correspondence should be addressed.
Preparation of $( \pm)-3$

2,2'-Biphenolate complex $( \pm)-3$ was prepared from ( \pm )-1 and lithium (1,1'-biphenyl)-2,2'-diolate in benzene followed by removal of unreacted 1 with alumina (ICN biochemicals) according to the literatures. ${ }^{5}$ The obtained complex was used in chromatographic separation as a benzene solution without further purification.

\section{Polymerization Procedure}

Polymerization was carried out in a glass ampule equipped with a three-way stopcock, and purified reagents were transferred into the ampule with syringes under a dry nitrogen atmosphere. The polymerization was typically carried out using zirconocene $3\left(8.0 \times 10^{-3}\right.$ $\mathrm{mmol})$, MAO (1.85 M, $1.3 \mathrm{mmol})$, and monomer (1.3 $\mathrm{mmol})$ in toluene at $30^{\circ} \mathrm{C}$. After mixing zirconocene and MAO in toluene at room temperature for $5 \mathrm{~min}$, a monomer was added. The polymerization was stopped by carefully adding $2 \mathrm{~mL}$ of methanol at $0^{\circ} \mathrm{C}$ and then the polymer was precipitated in a large amount of $1 \mathrm{~N}$ $\mathrm{HCl}$-methanol $(1: 6)$. The polymer was washed with methanol and dried in vacuo. Methanol insoluble polymer was obtained quantitatively.

\section{RESULTS AND DISCUSSION}

\section{Separation of $( \pm)-3$}

2,2'-Biphenolate complex $( \pm)-3$ was separated into enantiomers by HPLC on a silica-gel column coated with cellulose tris(3,5-dimethylphenylcarbamate) as a chiral stationary phase using the eluent, $n$-hexane-ethyl alcohol $=20: 1$ as shown in Figure $1 .^{6}$ Chromatographic separation was performed using a preparative column $(50 \times 2.0$ (i.d.) $\mathrm{cm})$ and JASCO PU 980 chromatograph equipped with a UV detector (JASCO UV 970, monitored at $295 \mathrm{~nm}$ ) and polarimetric detector (JASCO OR 990) at room temperature. A benzene solution of the racemic sample, including about $13 \mathrm{mg}$ of $( \pm)-3$ was injected into a chromatographic system (eluent, $n$-hexane-ethyl alcohol $=20: 1$; flow rate, $10 \mathrm{~mL} \mathrm{~min}^{-1}$ ). The purity of the recovered complex (+)- and (-)-3 was confirmed by chiral HPLC (Figure 2), ${ }^{1} \mathrm{H},{ }^{13} \mathrm{C} \mathrm{NMR}$, and elemental analyses; ${ }^{1} \mathrm{H}$ NMR $\left(500 \mathrm{MHz}, \mathrm{CDCl}_{3}\right) \delta$ $1.3-1.8\left(\mathrm{~m}, 8 \mathrm{H}, \mathrm{CH}_{2}\right), 2.10\left(\mathrm{~m}, 4 \mathrm{H}, \mathrm{CH}_{2}\right), 2.60(\mathrm{~m}, 4 \mathrm{H}$, $\left.\mathrm{CH}_{2}\right), 3.12\left(\mathrm{~m}, 2 \mathrm{H}, \mathrm{CH}_{2}\right), 3.28\left(\mathrm{~m}, 2 \mathrm{H}, \mathrm{CH}_{2}\right), 5.70(\mathrm{~s}$, $4 \mathrm{H}, \mathrm{Cp}-\mathrm{H})$, and $6.7-7.2\left(\mathrm{~m}, 8 \mathrm{H}\right.$, aromatic); ${ }^{13} \mathrm{C} \mathrm{NMR}$ $\left(125 \mathrm{MHz} \mathrm{CDCl}_{3}\right) \delta 161.7,131.9,131.8,130.3,128.3$, 


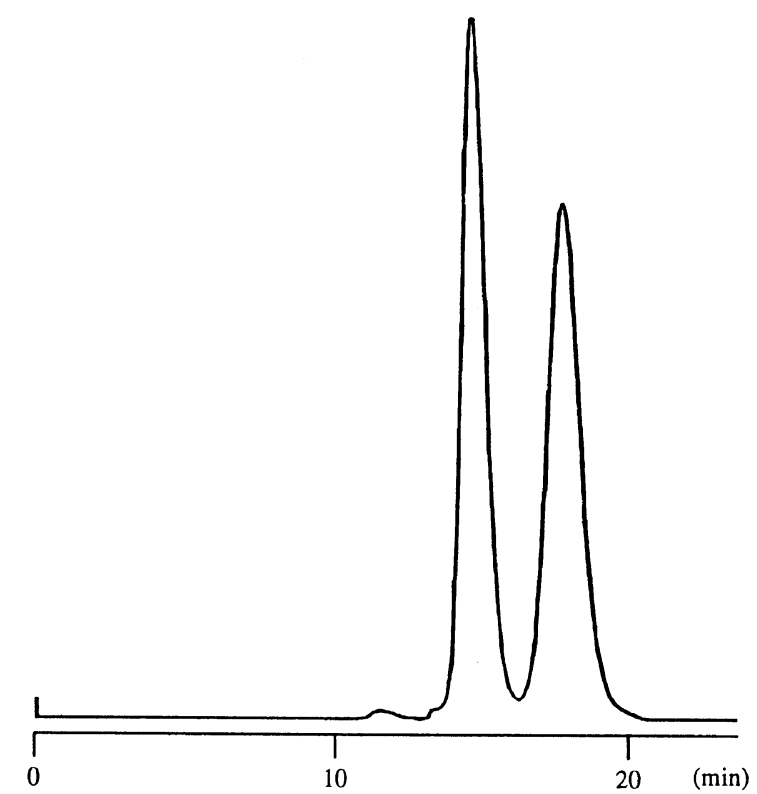

Figure 1. HPLC trace of zirconocene 3 on a silica-gel column coated with cellulose tris(3,5-dimethylphenylcarbamate). Column, $50 \times 2.0$ (i.d.) $\mathrm{cm}$; eluent, $n$-hexane-ethanol $=20: 1(\mathrm{v} / \mathrm{v})$; flow rate, $10 \mathrm{~mL} \mathrm{~min}^{-1}$. monitored at $295 \mathrm{~nm}$

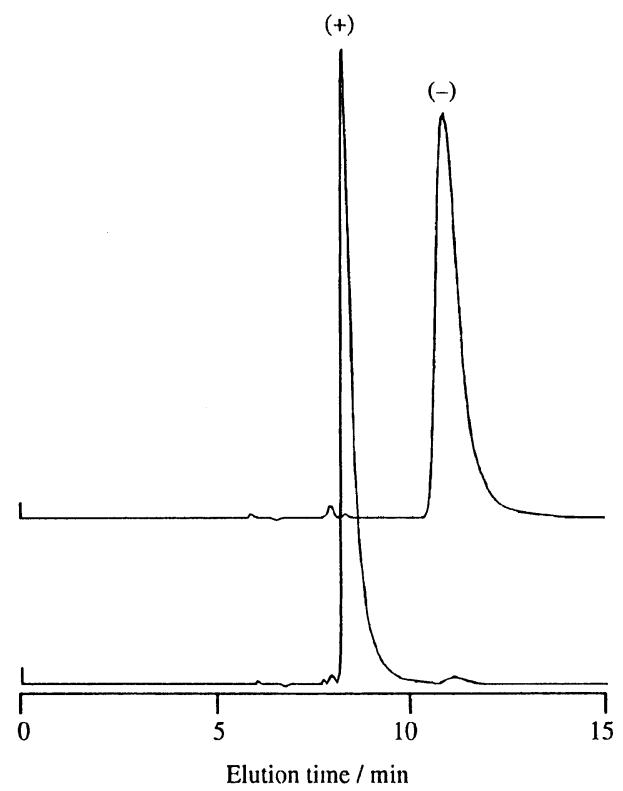

Figure 2. HPLC traces of (+)-3 (97\% ee) (a) and ( - )-3 (>99\%ee) on a silica-gel column coated with cellulose tris(3,5-dimethylphenylcarbamate). Column, $25 \times 0.46$ (i.d.) $\mathrm{cm}$; eluent, $n$-hexane ethanol $=$ $20: 1(\mathrm{v} / \mathrm{v})$; flow rate, $0.5 \mathrm{~mL} \mathrm{~min}^{-1}$; monitored at $295 \mathrm{~nm}$.

$128.2,123.0,119.2,118.6,114.6,106.2,27.5,23.6,22.8$, 22.33, and 22.27; Elemental Analysis. Found: $\mathrm{C}=$ $71.19 \%, \mathrm{H}=6.23 \%$ for $(+)-3$ and $\mathrm{C}=70.81 \%, \mathrm{H}=$ $6.38 \%$ for (-)-3. Calcd for $\mathrm{C}_{32} \mathrm{H}_{32} \mathrm{O}_{2} \mathrm{Zr}$ : $\mathrm{C}=71.20 \%$, $\mathrm{H}=5.98 \%$. The specific rotation $\left([\alpha]_{435}^{25}\right)$ of the isolated $(+)$ - and $(-)-3$ was estimated to be $+2200^{\circ}(c=0.12)$ and $-2000^{\circ}(c=0.07)$, respectively, in $\mathrm{CHCl}_{3}$. Figure 3 demonstrates the circular dichroism (CD) spectra of the enantiomers in $\mathrm{CHCl}_{3}$, which were mirror images of each other.

\section{Application of $\mathbf{3}$}

Waymouth et al. reported that the asymmetric cyclopolymerization of 1,5-hexadiene using the optically active

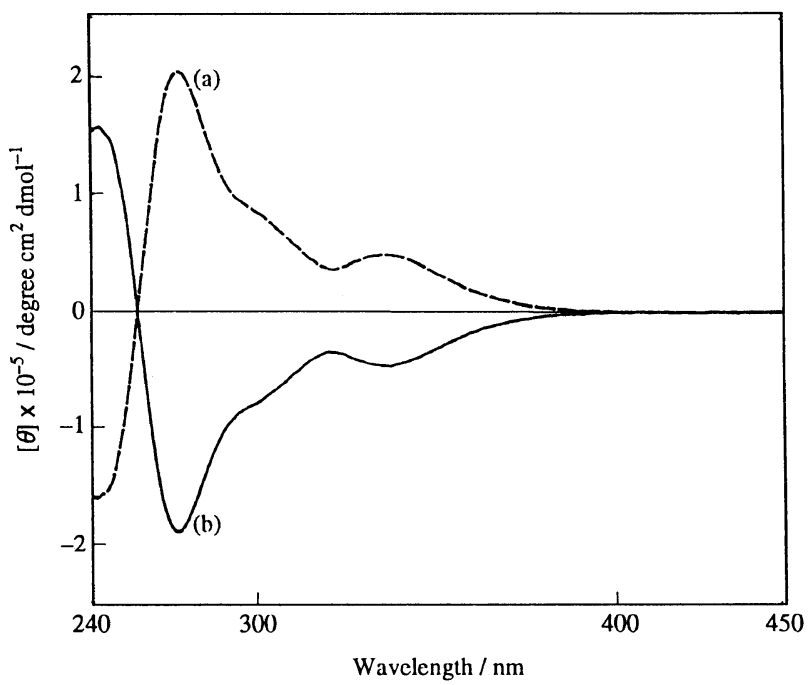

Figure 3. CD spectra of (+)-3 (a) and (-)-3 (b).

Table I. Cyclopolymerization of 1,5-hexadiene using optically active zirconocene catalyst $(3)^{a}$

\begin{tabular}{|c|c|c|c|c|c|}
\hline \multirow{2}{*}{ Entry } & \multirow{2}{*}{ Zirconocene } & \multirow{2}{*}{$\begin{array}{c}\text { [Monomer] } / \\
{[\mathrm{Al}] /[\mathrm{Zr}]}\end{array}$} & Yield $^{b}$ & Trans ${ }^{c}$ & {$[\alpha]_{435}{ }^{\mathrm{d}}$} \\
\hline & & & $\%$ & $\%$ & deg \\
\hline 1 & $(+)-3$ & $160 / 160 / 1$ & 34 & 73 & -40 \\
\hline 2 & $(-)-3$ & $170 / 180 / 1$ & 39 & 71 & +46 \\
\hline
\end{tabular}

${ }^{\text {a }}$ Polymerization was carried out using $\mathrm{MAO}$ as a cocatalyst in toluene at $30^{\circ} \mathrm{C}$ for $0.5 \mathrm{~h}$, [monomer] $=0.2 \mathrm{M}$. ${ }^{\mathrm{b}}$ Methanol insoluble and $\mathrm{CHCl}_{3}$ soluble part. ${ }^{\mathrm{c}}$ Determined by ${ }^{13} \mathrm{C}$ NMR. ${ }^{4} \mathrm{~d}$ Measured in $\mathrm{CHCl}_{3}$ at $25^{\circ} \mathrm{C}(c=0.50)$.

2,2'-binaphtholate complex $\mathbf{2}$ yields optically active poly(methylene-1,3-cyclopentane) (poly(MCP)) based on a main-chain chiral configuration. ${ }^{4,8}$ They obtained optically active poly(MCP)s possessing molar optical rotations $[\Phi]_{405}^{28}=+51^{\circ}$ and $-51^{\circ}\left(c=0.8, \mathrm{CHCl}_{3}\right)$ using $(R, R)-2$ and $(S, S)-2$, respectively. (+)-3 and (-)-3 complexes were also used for the polymerization of $1,5-$ hexadiene (Table I). After polymerization in the presence of excess methylaluminoxane (MAO) at $30^{\circ} \mathrm{C}$ for $0.5 \mathrm{~h}$ in toluene, methanol-insoluble and $\mathrm{CHCl}_{3}$-soluble poly(MPC)s were obtained in $34 \%$ and $39 \%$ yields, and showed specific rotations $[\alpha]_{435}^{25}=-40^{\circ}\left([\Phi]_{435}^{25}=-33^{\circ}\right)$ and $+46^{\circ}\left([\Phi]_{435}^{25}=+38^{\circ}\right)$, respectively. These values seem comparable to the results of Waymouth et al., taking into account differences of wavelengths for optical rotation. This may be because the binaphtholate and biphenolate ligands would not participate in the polymerization. ${ }^{4 \mathrm{~b}}$ The results indicate that the absolute configurations of $(+)-3$ and $(-)-3$ are $(S)$ and $(R)$, respectively, in comparison with those of $2,2^{\prime}$-binaphtholate complexes.

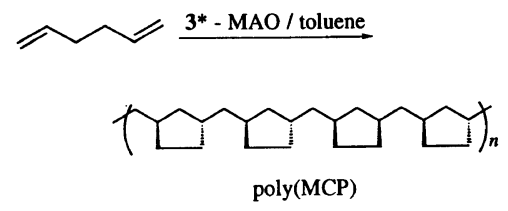

In conclusion, the first isolation of optically pure ethylenebis(4,5,6,7-tetrahydro-1-indenyl)zirconium 2,2'biphenolate complexes, $(+)-3$ and $(-)-3$, was accom- 
plished by HPLC using cellulose tris(3,5-dimethylphenylcarbamate) as the chiral stationary phase, and its ability to function as an asymmetric catalyst was demonstrated in the asymmetric cyclopolymerization of 1,5-hexadiene. A new method for the preparation of enantiomerically pure ansa-zirconocene complexes was established.

\section{REFERENCES}

1. (a) M. T. Didiuk, J. P. Morken, and A. H. Hoveyda, J. Am Chem. Soc., 117, 7097 (1995). (b) M. S. Visser and A. H. Hoveyda, Tetrahedron, 51, 4383 (1995). (c) W. Kaminsky, A. Ahlers, and N. Möller-Lindenhof, Angew. Chem., Int. Ed. Engl., 28, 1216 (1989). (d) P. Pino, P. Cioni, and J. Wei, J. Am. Chem. Soc., 109, 6189 (1987). (e) W. Kaminsky, K. Küpler, and S. Niedoba, Makromol. Chem., Makromol Symp., 3, 377 (1986).

2. (a) F. R. W. P. Wild, M. Wasiucionek, G. Huttner, and H. H. Brinzinger, J. Organomet. Chem., 288, 63 (1985). (b) S. Collins, B. A. Kuntz, N. J. Taylor, and D. G. Ward, J. Organomet. Chem.,
342, 21 (1988)

3. The asymmetric reactions using optically active $\mathbf{2}$ have been reported. (a) P. Pino, M. Galimberti, P. Prada, and G. Consiglio, Makromol. Chem., 191, 1677 (1990). (b) M. S. Visser, J. P. A. Harrity, and A. M. Hoveyda, J. Am. Chem. Soc., 118, 3779 (1996).

4. (a) G. W. Coates and R. M. Waymouth, J. Am. Chem. Soc., 113, 6270 (1991). (b) G. W. Coates and R. M. Waymouth, J. Am. Chem. Soc., 115, 91 (1993).

5. (a) F. R. W. P. Wild, L. Zsolnai, Huttner, and H. H. Brinzinger, J. Organomet. Chem., 232, 233 (1982). (b) R. B. Grossman, W. M. Davis, and S. L. Buchwald, J. Am. Chem. Soc., 113, 2321 (1991). (c) A. Schäfer, E. Karl, L. Zsolnai, G. Huttner, and H. H. Brinzinger, J. Organomet. Chem., 328, 87 (1987).

6. S. Habaue, H. Sakamoto, and Y. Okamoto, Chem. Lett., 383 (1996).

7. (a) E. Yashima and Y. Okamoto, Bull. Chem. Soc. Jpn., 68, 3289 (1995). (b) Y. Okamoto and Y. Kaida, J. Chromatogr. A, 666, 403 (1994). (c) Y. Okamoto, M. Kawashima, and K. Hatada, J. Chromatogr., 363, 173 (1986).

8. (a) G. Wullf, Angew, Chem., Int. Ed. Engl., 28, 21 (1989). (b) Y. Okamoto and T. Nakano, Chem. Rev., 94, 349 (1994). 